\title{
Evolution of microstructure in AZ91 alloy processed by high-pressure torsion
}

\author{
Ahmed S. J. Al-Zubaydi ${ }^{1,2} \cdot$ Alexander P. Zhilyaev ${ }^{3,4} \cdot$ Shun C. Wang ${ }^{1} \cdot$ \\ P. Kucita ${ }^{1} \cdot$ Philippa A. S. Reed ${ }^{1}$
}

Received: 25 September 2015/ Accepted: 6 December 2015/Published online: 21 December 2015

(C) The Author(s) 2015. This article is published with open access at Springerlink.com

\begin{abstract}
An investigation has been conducted on AZ91 magnesium alloy processed in high-pressure torsion (HPT) at 296,423 and $473 \mathrm{~K}$ for different numbers of turns. The microstructure has altered significantly after processing at all processing temperatures. Extensive grain refinement has been observed in the alloy processed at $296 \mathrm{~K}$ with apparent grain sizes reduced down to $35 \mathrm{~nm}$. Segmentation of coarse grains by twinning has been observed in the alloy processed at $423 \mathrm{~K}$ and $473 \mathrm{~K}$ with average apparent grain sizes of $180 \mathrm{~nm}$ and $250 \mathrm{~nm}$. Substantial homogeneity in microhardness has been observed in the alloy processed at $296 \mathrm{~K}$ compared to that found at $423 \mathrm{~K}$ and $473 \mathrm{~K}$. The ultrafine-grained AZ91 alloy exhibited a significant
\end{abstract}

Ahmed S. J. Al-Zubaydi

asaz1e11@soton.ac.uk

Alexander P. Zhilyaev

alexz@anrb.ru

Shun C. Wang

wangs@ soton.ac.uk

P. Kucita

pk4v07@soton.ac.uk

Philippa A. S. Reed

p.a.reed@soton.ac.uk

1 Materials Research Group, Faculty of Engineering and the Environment, University of Southampton, Southampton SO17 1BJ, UK

2 Branch of Materials Science, Department of Applied Sciences, University of Technology, Baghdad, Iraq

3 Institute for Problems of Metals Superplasticity, Russian Academy of Sciences, Khalturina 39, Ufa, Russia 450001

4 Research Laboratory for Mechanics of New Nanomaterials, St. Petersburg State Polytechnical University, St. Petersburg, Russia 195251 dependence of the yield strength on grain size as shown by the microhardness measurements, and it obeys the expected Hall-Petch relationship. The alloying elements, fraction of nano-sized particles of $\beta$-phase, and the dominance of basal slip and pyramidal modes have additional effects on the strengthening of the alloy processed at $296 \mathrm{~K}$.

\section{Introduction}

Magnesium alloys are promising alternatives to replace denser materials, such as steel and aluminium alloys, with the objective of meeting requirements to save fuel by manufacturing light weight/high strength parts [1]. The mechanisms of deformation in magnesium alloys at room temperature are basal slip and twinning, which result in a limitation in their workability at room temperature [2]. The limited ductility and workability of these alloys can be improved at higher temperatures by the activation of additional slip systems [1]. Thermo-mechanical processing is used to improve the workability of these alloys, although such processing is associated with grain growth and a greater consumption of energy [3]. Several processing routes have been introduced to achieve optimization of the microstructure, and these routes include dynamic recrystallization under high-temperatures in ECAP processing [4], HPT processing [5, 6], ECAP processing at relatively low temperatures assisted by a back-pressure [7], or through the use of a higher channel angle of pressing die in ECAP processing [8]. The majority of the earlier work in SPD processing of magnesium alloys, especially for AZ91 alloy, has been conducted using ECAP at elevated temperatures $(\geq 473 \mathrm{~K})[2,4,9]$ with resultant grain refinement being achieved in the micrometre range. The AZ91 alloy (Mg-9wt\%Al-1wt\%Zn-0.3wt\%Mn) is a common alloy in 
the Mg-Al-Zn family. This alloy has a good strength-todensity ratio, good corrosion resistance and ease of production and machining [3]. To date, only one investigation has been conducted on $\mathrm{Mg}-9 \mathrm{wt} \% \mathrm{Al}$ alloy [6] using HPT at room temperature. The development of microstructure and microhardness across horizontal and vertical cross-sections of AZ91 samples processed by HPT has not been reported to date. This research describes the microstructural homogeneity and development of microhardness in AZ91 alloy after processing by HPT at different processing temperatures. The dislocation density, distribution of $\beta$ phase and Hall-Petch relationship have also been investigated.

\section{Experimental materials and procedures}

AZ91 alloy (Mg-9 \%Al-1 \%Zn) in the form of an extruded rod was used in this work, the alloy was supplied by Magnesium Elektron Co. (Manchester, UK). Thin discs were made of the extruded rod with thicknesses of $1.5 \mathrm{~mm}$ and final thicknesses of $0.85 \mathrm{~mm}$. The HPT processing was conducted at 296, 423 and $473 \mathrm{~K}$ using a HPT facility that has been previously discussed in detail elsewhere [10]. The HPT processing was conducted under a quasi-constrained condition at a speed of $1 \mathrm{rpm}$ using an applied pressure of $3.0 \mathrm{GPa}$ for differing numbers of turns: $N=1 / 2,1,5$ and 10 turns. The as-received and processed microstructures were observed using optical microscopy (OM, OLYMPUSBX51, Japan) and scanning electron microscopy (SEM, JEOL JSM-6500F, Japan). Subsequently, a transmission electron microscope (TEM, JEOL JEM-3010) was used for microstructural observation of the alloy after HPT processing. The chemical compositions of the as-received and processed alloy were analysed using energy-dispersive spectroscopy (EDS). The area fraction and average size of the $\beta$-phase particles in the as-received alloy and processed alloy were determined by ImageJ software using a point count technique [11]. X-ray diffraction was used to determine the crystallite size and dislocation density in the processed alloy using an XRD facility (D2 Phaser, Germany). The diffraction data were analysed using Rietveld refinement based software program (MAUD). Microstructural observations and microhardness testing were conducted over the horizontal and vertical cross-sections that are illustrated schematically in Fig. 1a, b. The microhardness measurements of the processed disc were conducted using a Vickers microhardness tester (FM-300, Japan) and using an applied load of $100 \mathrm{gf}$ and a dwell time of $15 \mathrm{~s}$. The microhardness data were recorded at separation distances of 0.3 and $0.1 \mathrm{~mm}$ throughout the entire horizontal and vertical cross-sections, as reported earlier [5, 12].
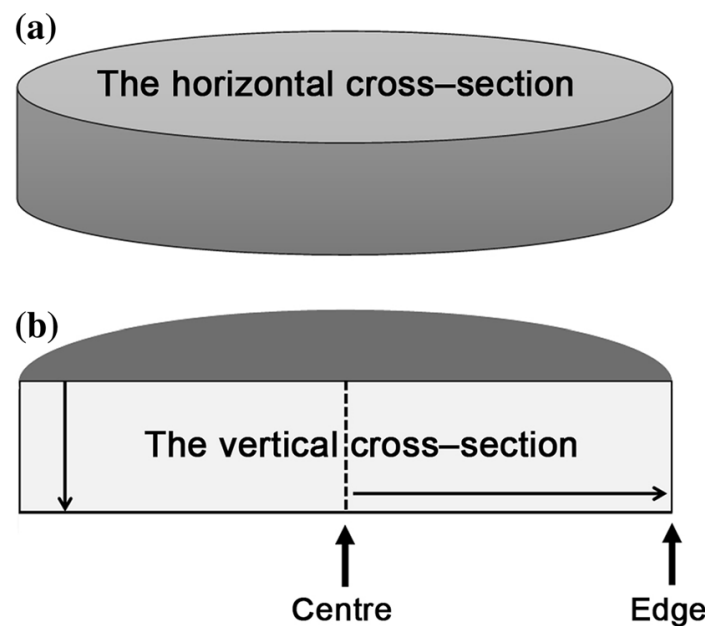

Fig. 1 An illustration of a HPT disc shows a the horizontal crosssection, and b The vertical cross-section. These cross-sections were used in the microstructural and microhardness observations. The arrow from the centre to the edge refers to the longitudinal (radial) direction, whereas the arrow from the upper surface to lower surface refers to the through-thickness (vertical) direction

\section{Experimental results}

The microstructure of the AZ91 magnesium alloy prior to and after HPT processing is shown in Fig. 2. The as-received AZ91 alloy has an average grain size of $30 \mu \mathrm{m}$ and an average value of Vickers microhardness of $70 \pm 5$. The initial and processed microstructures consist of two main phases: $\alpha$-Mg matrix, $\beta$-phase and $\mathrm{Al}_{8} \mathrm{Mn}_{5}$ particles as shown in Fig. 2a, b. The chemical analysis obtained by EDS of alloying elements in the alloy processed at $296 \mathrm{~K}$ for $N=5$ turns is shown in Fig. 3. The alloy constituents were identical before and after HPT as shown earlier [13]. The processed microstructure at $296 \mathrm{~K}$ showed extensive grain refinement, and the original decoration of the grain boundaries by $\beta$-phase disappeared with increasing number of turns as shown in Fig. $2 b$, c. The $\beta$-phase fragmented into nano-sized particles as observed in Fig. $2 b-d$ and appears aligned along the direction of torsional straining. A strong degree of grain refinement after processing at $296 \mathrm{~K}$ was observed with an apparent grain size down to 500 and $50 \mathrm{~nm}$ observed after $N=1 / 2$ and 1 turn, respectively, as shown in Fig. 2e, f. A reduction in the crystallite size from 60 to $35 \mathrm{~nm}$ was found with increasing number of turns up to $N=10$ turns. The processed microstructures at $296 \mathrm{~K}$ across the vertical cross-sections are shown in Fig. 4. The microstructure seems slightly deformed with the presence of twinning as shown in Fig. 4a. Shear bands decorated by the $\beta$-phase were observed aligned parallel to the radial direction across the vertical cross-section as observed in Fig. 4b. Recorded peaks by XRD as shown in Fig. 5 are 

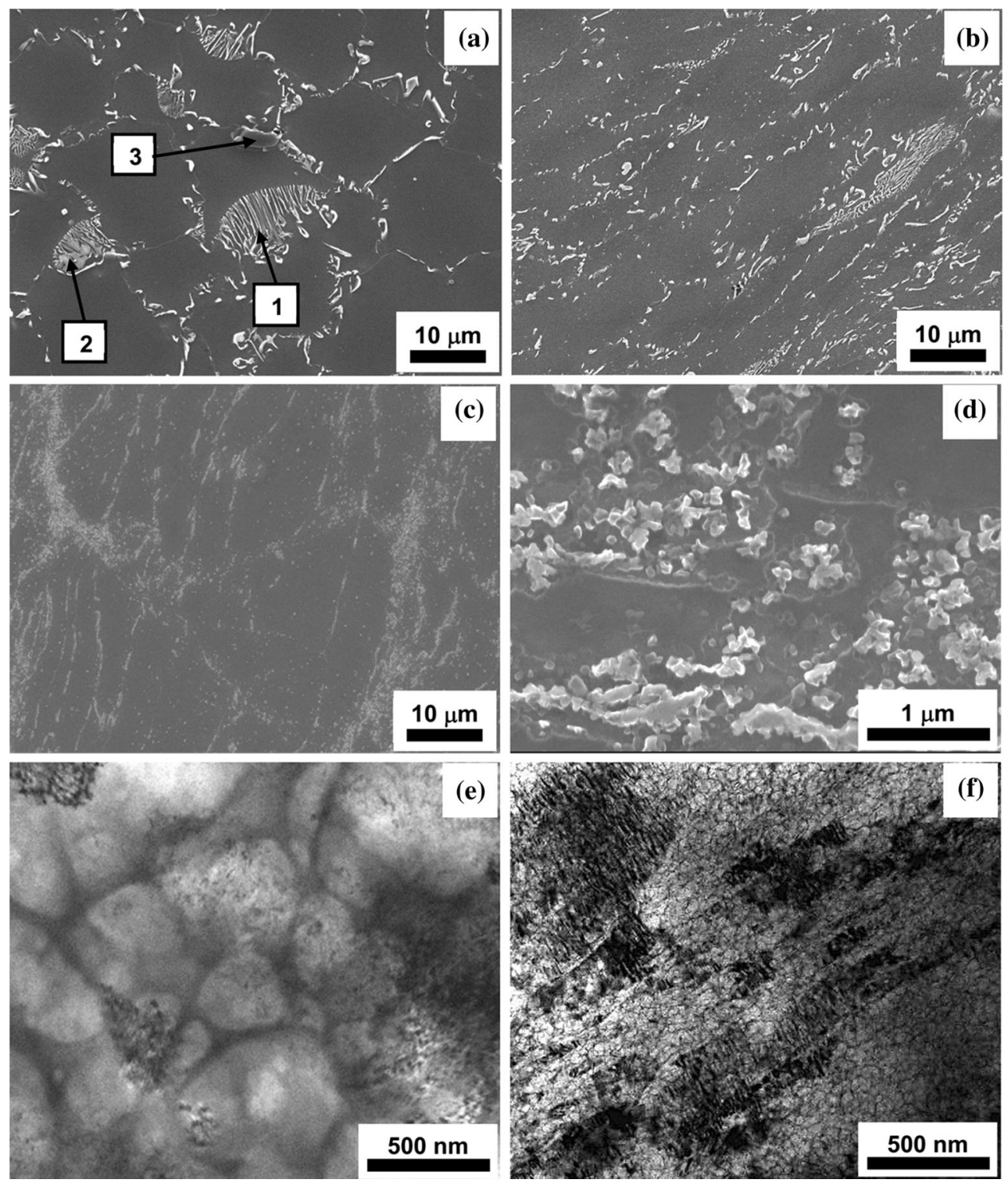

Fig. 2 Microstructural observations using SEM for a the as-received alloy, b the alloy processed for $N=1$ turn $(296 \mathrm{~K})$, c the alloy processed for $N=10$ turns $(296 \mathrm{~K})$ and $\mathbf{d}$ the nano-sized particles of $\beta$-phase in the alloy processed for $N=10$ turns (296 K), and TEM

observation of the alloy processed for e $N=1 / 2$ turn $(296 \mathrm{~K})$ and f $N=1$ turn $(296 \mathrm{~K})$. The corresponding numbers $(1,2,3)$ in the micrograph a represent the lamellar, agglomerate forms of the $\beta$ phase $\left(\mathrm{Mg}_{17} \mathrm{Al}_{12}\right)$ and $\mathrm{Al}_{8} \mathrm{Mn}_{5}$ particle, respectively

prismatic planes $(10 \overline{1} 0),(11 \overline{2} 0),(20 \overline{2} 0)$, basal plane

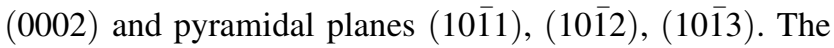
microstructures of the alloy processed at 423 and $473 \mathrm{~K}$ are shown in Fig. 6. The samples showed twinning, and the distribution of twinning increased and spread gradually with increasing number of turns. The microstructures were effectively refined by the segmentation of the coarse grains by twinning as observed in Fig. 6a, b. However, grain growth has been observed at $473 \mathrm{~K}$ with increasing number of turns up to $N=5$ turns as shown in Fig. 6b. The apparent area fraction has increased (which may reflect a

sampling effect once the second phase is more homogeneously distributed), and the average size of the $\beta$-phase particles has been refined down to $200 \mathrm{~nm}$ in the processed alloy compared to the as-received alloy as shown in Fig. 7. A gradual development in the microhardness over the horizontal and vertical cross-sections has been achieved with increasing number of turns up to $N=10$ turns as shown in Figs. 8 and 9. The distributions of microhardness were relatively lower for the alloy processed at 423 and $473 \mathrm{~K}$ than at $296 \mathrm{~K}$. A significant increase in the microhardness has been observed as shown 
(a)
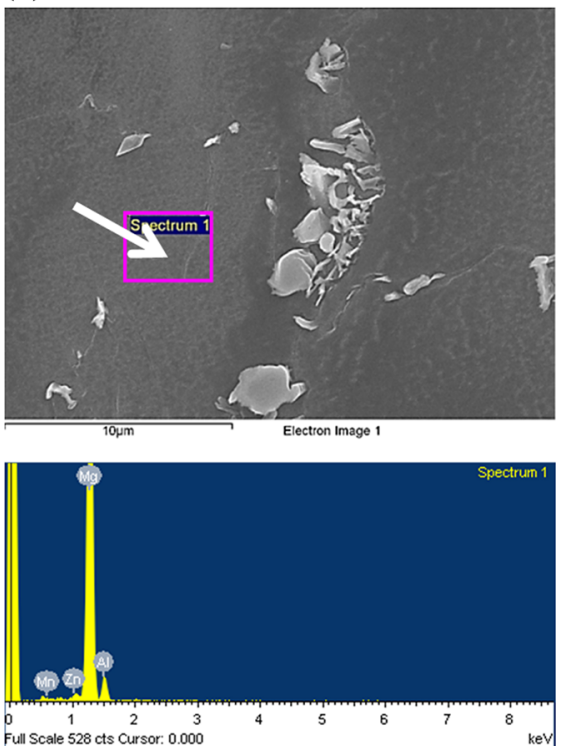

\begin{tabular}{|c|c|}
\hline Element & wt. \% \\
\hline Mg & 87.74 \\
\hline Al & 10.53 \\
\hline Zn & 1.31 \\
\hline Mn & 0.42 \\
\hline
\end{tabular}

(b)
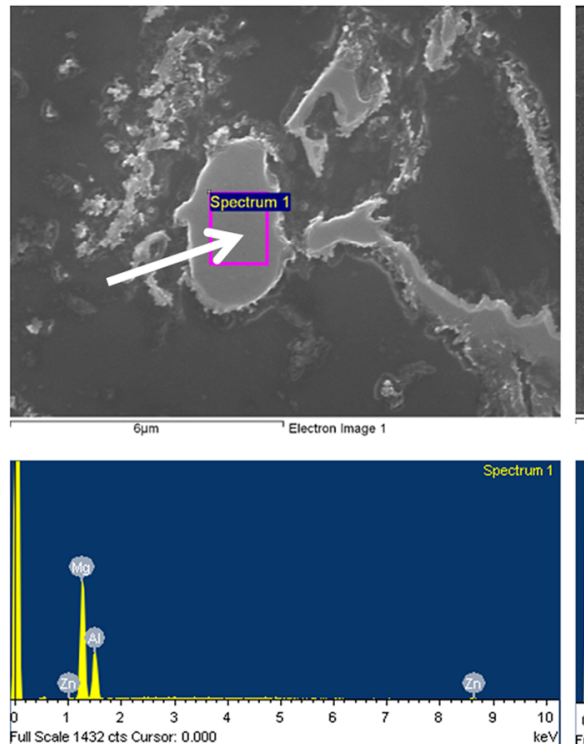

\begin{tabular}{|c|c|}
\hline Element & wt.\% \\
\hline $\mathbf{M g}$ & $\mathbf{5 8 . 2 2}$ \\
\hline $\mathrm{Al}$ & $\mathbf{4 0 . 2 0}$ \\
\hline $\mathrm{Zn}$ & $\mathbf{0 . 9 1}$ \\
\hline $\mathbf{M n}$ & $\mathbf{0 . 6 7}$ \\
\hline
\end{tabular}

(c)
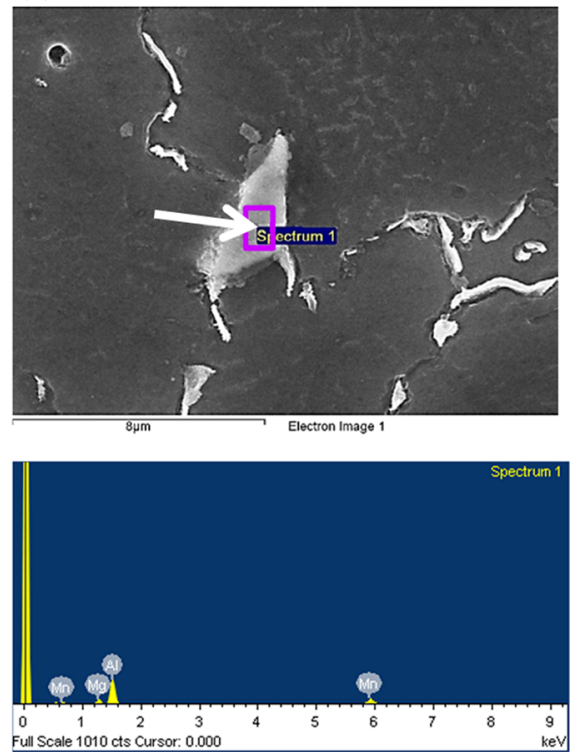

Fig. 3 The chemical analysis with weight fractions of the alloy processed at $296 \mathrm{~K}$ for $N=5$ turns showing a $\alpha$-Mg matrix, b $\beta$-phase $\left(\mathrm{Mg}_{17} \mathrm{Al}_{12}\right)$, c $\mathrm{Al}_{8} \mathrm{Mn}_{5}$ particle
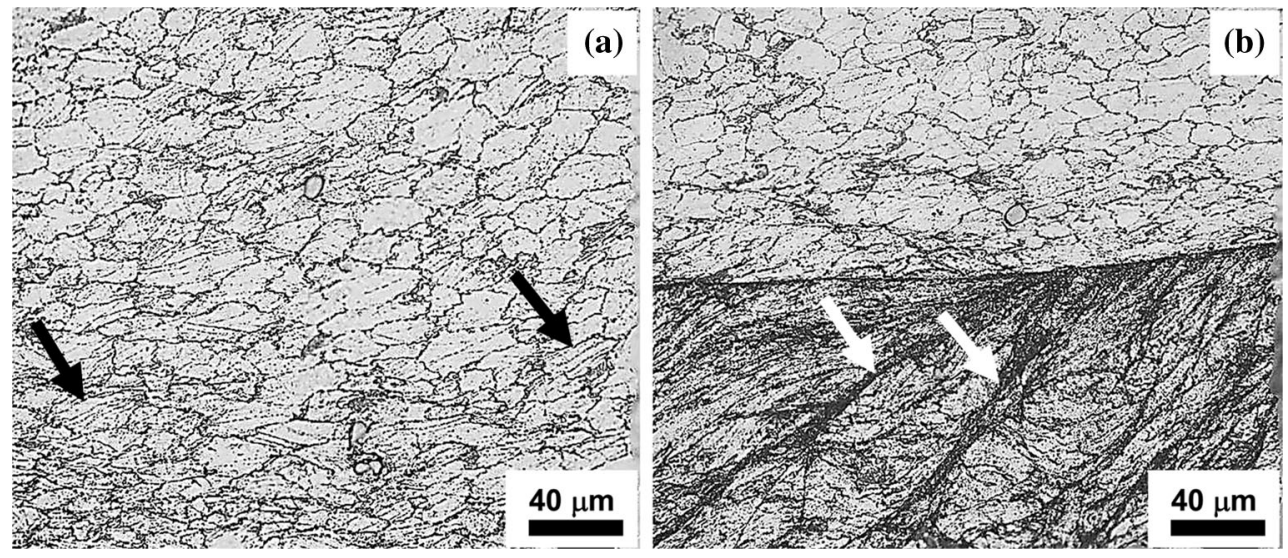

Fig. 4 The microstructures of the alloy processed at $296 \mathrm{~K}$ as observed along the vertical cross-sections for $\mathbf{a} N=1$ turn and $\mathbf{b} N=5$ turns. The black and white arrows refer to the twinning and shear bands decorated by the $\beta$-phase, respectively

in Fig. 10, with increasing equivalent strain imposed during HPT for the alloy processed at $296 \mathrm{~K}$. A significant dependency of the microhardness on the crystallite size of the AZ91 alloy processed at $296 \mathrm{~K}$ is shown in Fig. 11. The lower processing temperature leads to finer crystallite size, higher microhardness and dislocation density, and at elevated temperatures, these outcomes decreased significantly as the number of turns increased as shown in Fig. 12.

\section{Discussion}

\section{Feasibility of HPT processing of AZ91 magnesium alloy}

The TEM and XRD revealed the occurrence of extensive grain refinement in the AZ91 alloy due to the imposition of a very high plastic strain by HPT at $296 \mathrm{~K}$. However, for the sample processed for $N=1 / 2$ turn, it is noteworthy that the 

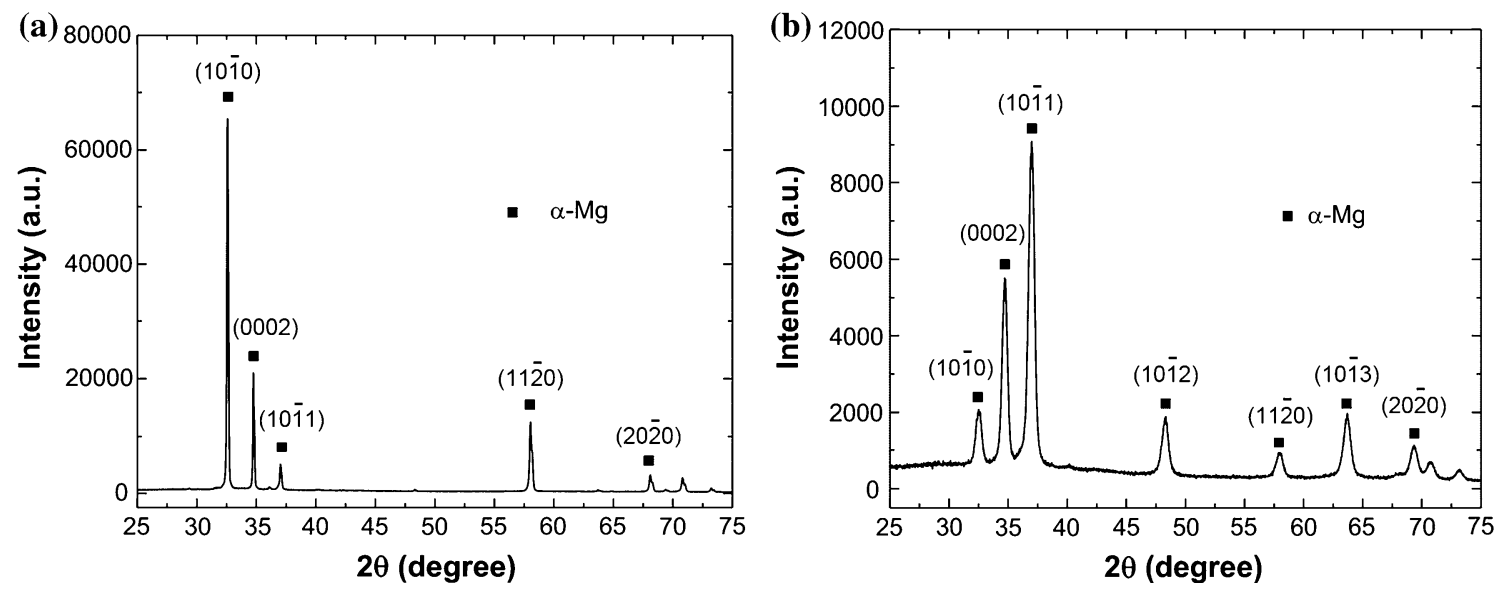

Fig. 5 XRD diffraction patterns for a the as-received alloy and $\mathbf{b}$ the alloy processed at $296 \mathrm{~K}$ for $N=10$ turns
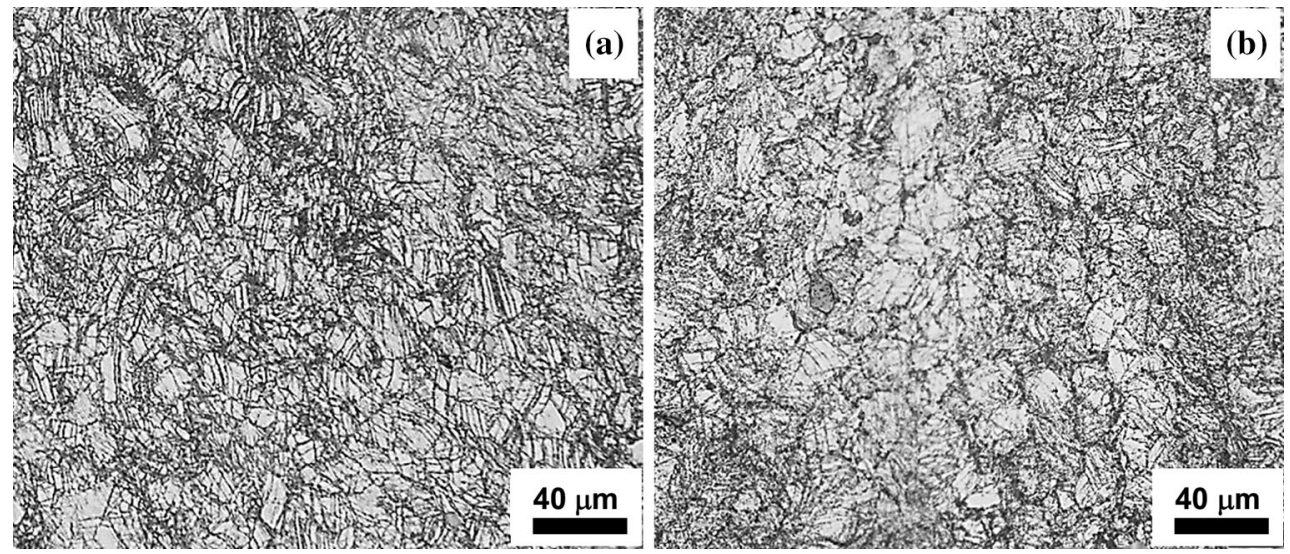

Fig. 6 The microstructures of the alloy as observed across the horizontal cross-sections after HPT processing at a $423 \mathrm{~K}(N=5$ turns) and b $473 \mathrm{~K}(N=5$ turns $)$

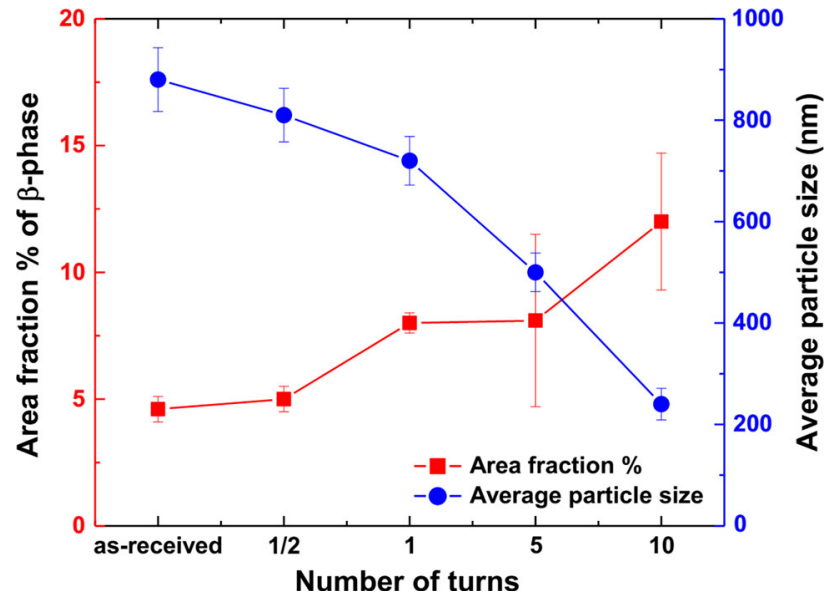

Fig. 7 The area fraction and average size of the $\beta$-phase particles in the as-received alloy and processed alloy at $296 \mathrm{~K}$ for different number of turns

value of the crystallite size obtained by XRD was significantly lower than the apparent grain size measured by TEM. This difference between the measurements via XRD and
TEM is expected in SPD-processed materials, because the grains in these materials are made of subgrains and/or dislocation cells. Thus, coherent scattering of the X-ray from these substructures represents the (smaller) mean crystallite size rather than grains which can be more easily observed in TEM [14]. The feasibility of HPT processing at $296 \mathrm{~K}$ for the AZ91 magnesium alloy can be attributed to the presence of hydrostatic pressure, which prevents propagation of fracture during processing [6-8]. Furthermore, the geometry of the processing zone constrains the alloy within a specific volume as illustrated earlier and thus activation of twinning $[8,15,16]$. The XRD observations indicate the orientation of the processed microstructure towards twinning and basal deformation modes under HPT conditions that facilitate processing at room temperature [16]. The unidirectional nature of straining during HPT processing may have contributed to re-orientation of the microstructure towards easy slip [17]. The twinning activity has persisted in the processed alloy at $296 \mathrm{~K}$ with increasing number of turns, which confirms its accommodation for the higher imposed strain produced by HPT [18]. 

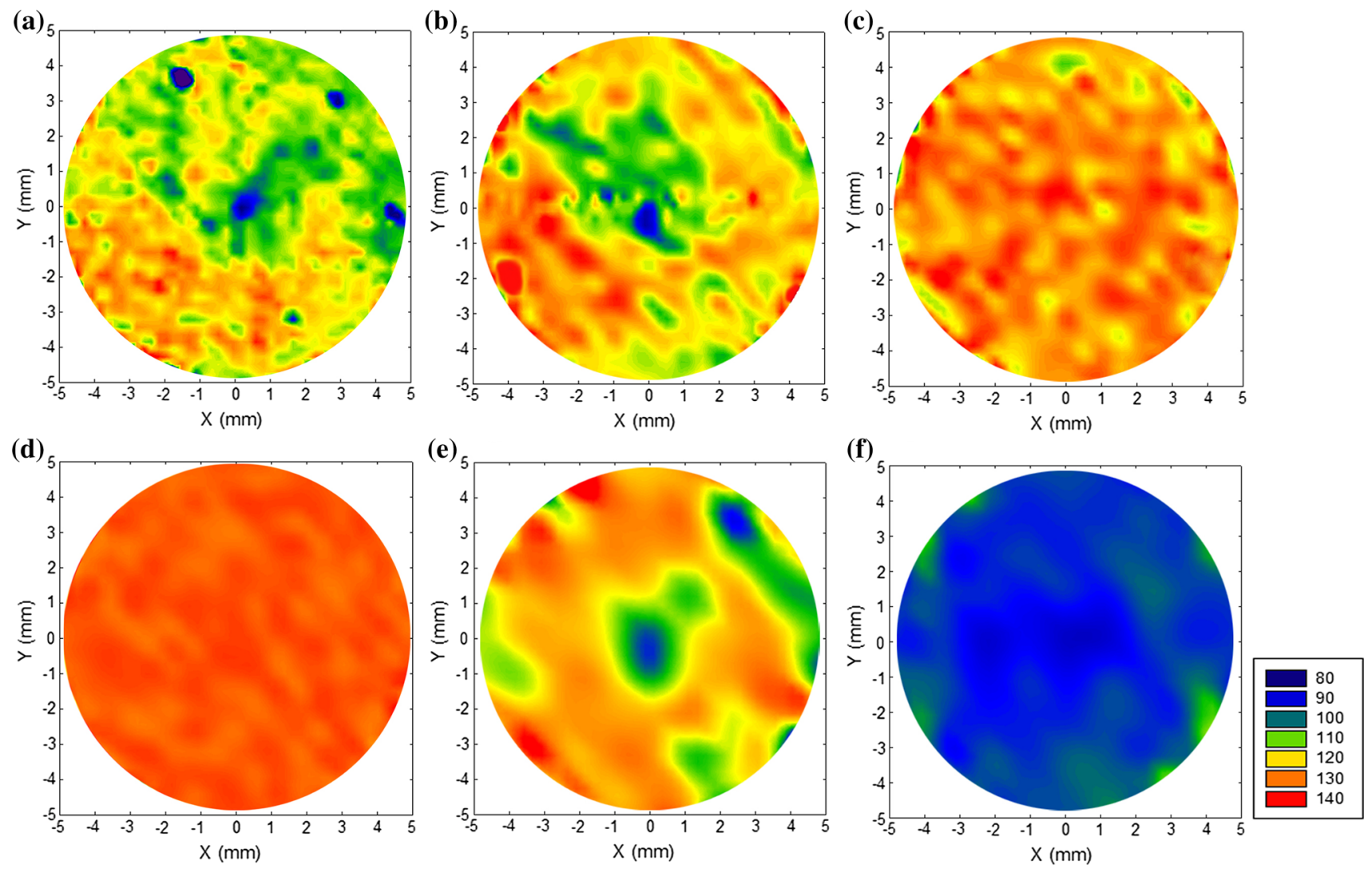

Fig. 8 The colour-coded maps of the microhardness over the horizontal cross-sections of the AZ91 discs processed forf a $N=1$ / 2 turn $(296 \mathrm{~K})$, b $N=1$ turn $(296 \mathrm{~K})$, c $N=5$ turns $(296 \mathrm{~K})$, d $N=10$ turns $(296 \mathrm{~K}), \mathbf{e} N=10$ turns $(423 \mathrm{~K})$ and $\mathbf{f} N=10$ turns $(473 \mathrm{~K})$. The small inset in the figure shows the scale of the microhardness with regard to each colour (Color figure online)
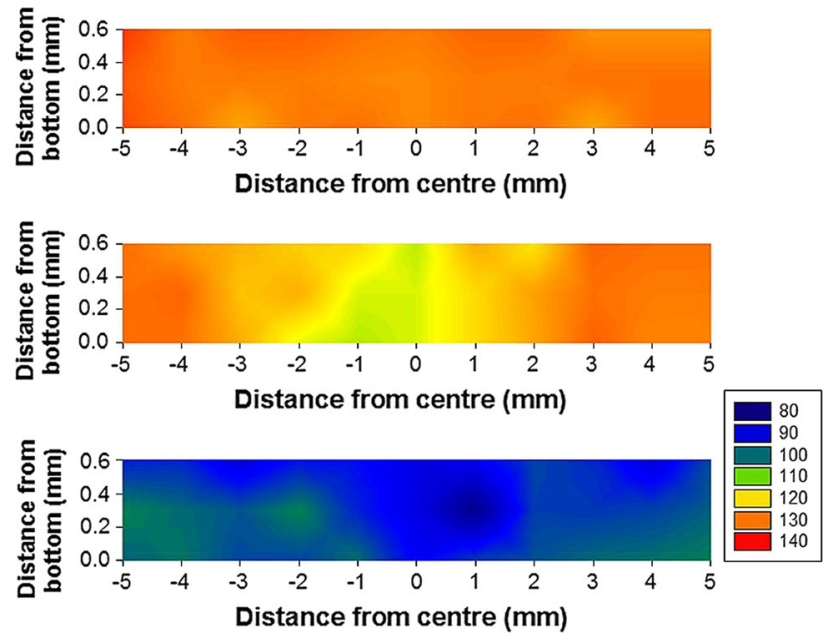

Fig. 9 The colour-coded maps of the microhardness distributions over the vertical cross-sections of the AZ91 discs processed for $N=10$ turns at $296 \mathrm{~K}$ (upper), $423 \mathrm{~K}$ (centre) and $473 \mathrm{~K}$ (lower). The small inset in the figure shows the scale of the microhardness with regard to each colour (Color figure online)

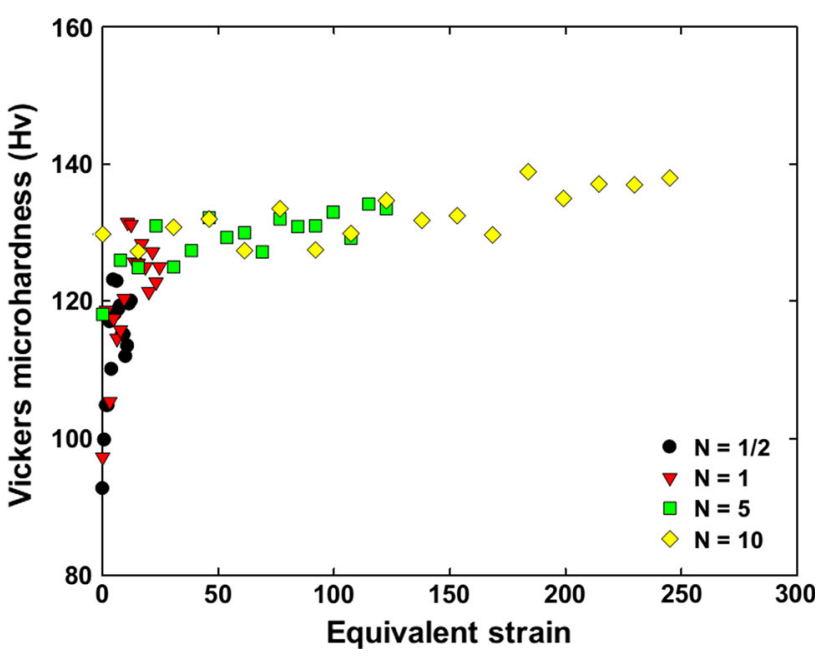

Fig. 10 Correlation of the measured microhardness with the equivalent strain imposed by HPT processing for the alloy processed at $296 \mathrm{~K}$ for different number of turns 


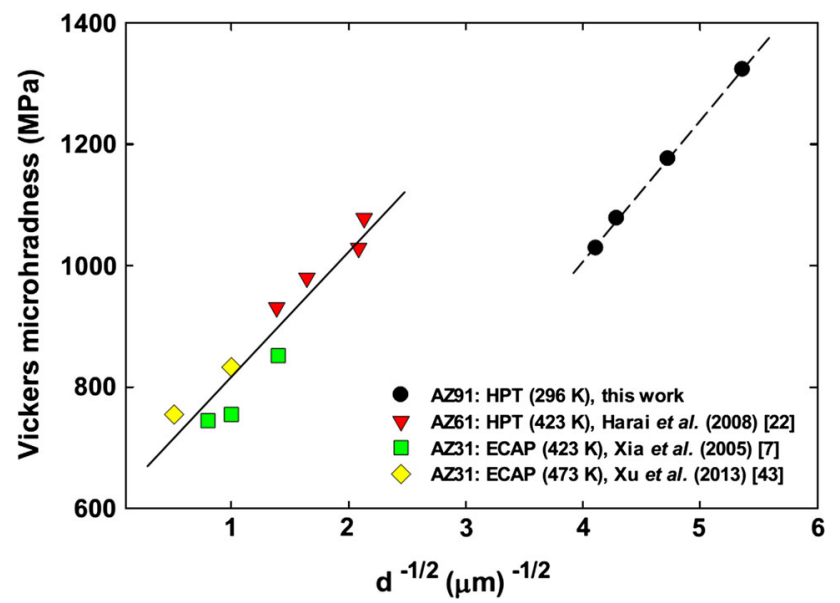

Fig. 11 The Hall-Petch relationship for the ultrafine-grained AZ91 alloy in the current work and for AZ31 and AZ61 alloys processed by HPT and ECAP

\section{Grain refinement in AZ91 alloy}

The relatively high content of aluminium in the AZ91 magnesium alloy leads to a significant reduction in the stacking fault energy through the solute-dislocation interaction and results in smaller grain sizes under SPD processing [19]. The effect of dynamic recovery was absent as the alloy has been processed at room temperature. It is anticipated that the homogeneity developed gradually with further straining at room temperature as mentioned by several investigators [20-23]. The grain refinement in the processed alloy at $423 \mathrm{~K}$ has developed efficiently by twinning intersections and the grain subdivision mechanism. At this temperature, dynamic recrystallization was absent or had a minor effect on the refinement process compared to the twinning activity. It is likely that dynamic recrystallization may have contributed to grain refinement in the processed alloy at $473 \mathrm{~K}$. However, the formation and fragmentation of twinning appears to be the dominant mechanism for refinement at $473 \mathrm{~K}$. The HPT-processed alloy at 423 and $473 \mathrm{~K}$ has significantly refined apparent grain sizes of 180 and $250 \mathrm{~nm}$, respectively, which are finer than in the previously reported ECAP [20, 24-26], FSP [27] and ARB-processed alloys [28]. In the aforementioned SPD techniques, grain refinement occurs mainly by dynamic recrystallization with resultant microstructures of micrometre size grains. The severe levels of deformation in the alloy and the deformation incompatibility between $\alpha$ $\mathrm{Mg}$ matrix and $\beta$-phase have resulted in fragmentation of the $\beta$-phase [29]. The significant dispersion of nano-sized particles of the $\beta$-phase during processing had a pinning effect on grain growth at a higher number of turns and elevated temperatures [23]. The alloy processed at $296 \mathrm{~K}$ showed microstructural homogeneity at the initial stage of
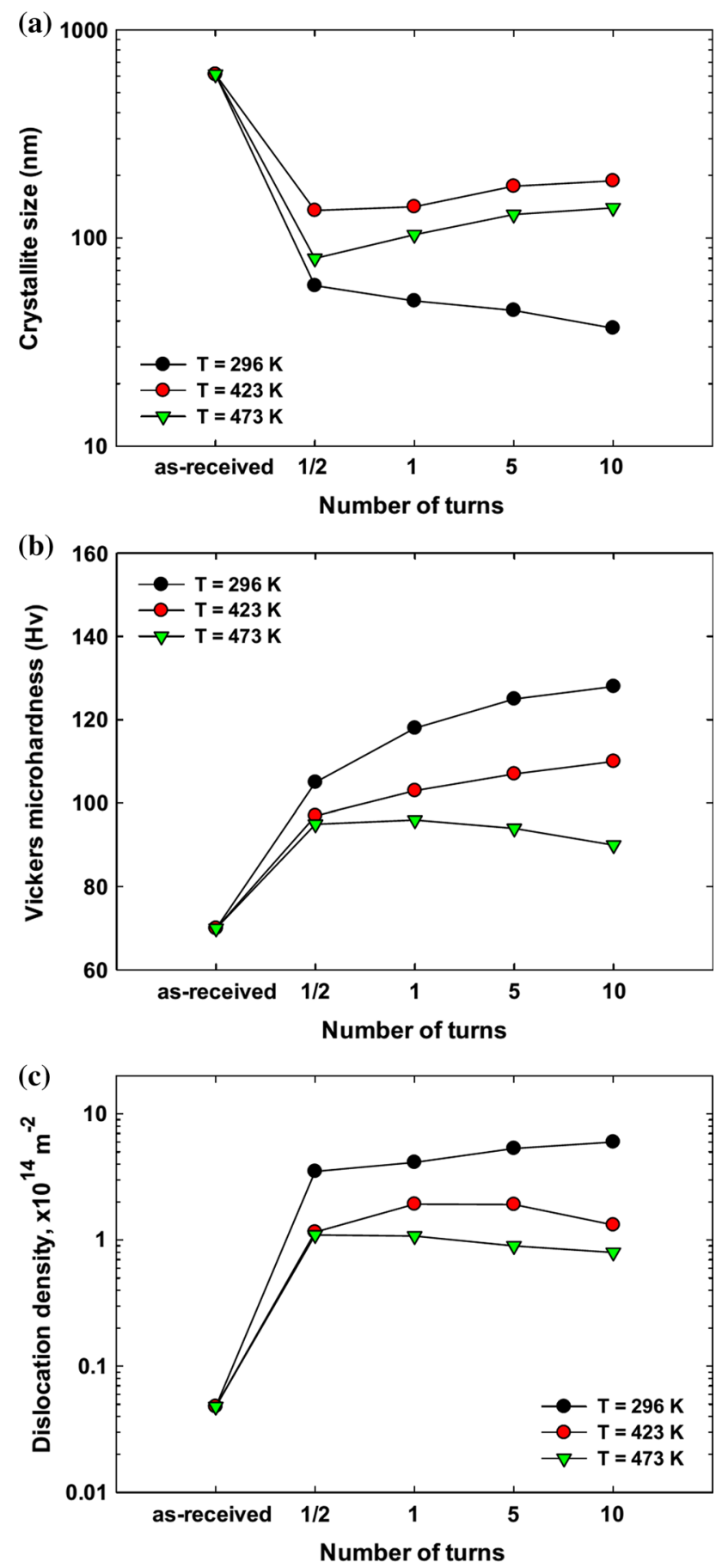

Fig. 12 The overall variation in the average a crystallite size, b dislocation density and c microhardness for the AZ91 alloy after HPT at different processing temperatures

HPT processing rather than the heterogeneity observed in the alloy processed at 423 and $473 \mathrm{~K}$, which required further processing turns and/or higher processing temperature to achieve a reasonable homogeneity [10]. The temperature rise expected during HPT processing at room temperature does not exceed $293 \mathrm{~K}$ for samples processed 
at $296 \mathrm{~K}$ for $N=10$ turns. This value of temperature rise has been calculated using the equation stated in [30], and is similar to the experimental value $(290 \mathrm{~K})$ measured directly from the thermocouple located in the upper anvil. The low value of temperature rise can be attributed to (1) the heat loss from relatively small samples in contact with the much larger HPT anvils and (2) due to the low strain rates of deformation in HPT processing [31]. A further factor, making the heat generated low, is the lower friction expected between the relatively lower strength magnesium alloy and the high strength (high speed tool steel) anvils $[15,31]$. As a result, any temperature rise due to processing is considered negligible and unlikely to produce any occurrence of recrystallization or grain growth during processing at room temperature [32].

\section{Development of microhardness}

The initial heterogeneity of microstructures leads to an initial heterogeneity in the distribution of microhardness $[10,33,34]$. The difference in grain sizes at the centre and edge regions was diminished by further straining, where a gradual evolution towards homogeneity was found in the observed microstructure and microhardness at both centre and edge regions at a higher number of turns [10, 35]. The existence of misalignment between the anvils at a high number of turns causes an additional deformation at the centre region of the processed disc, which appears as an increase in the measured microhardness [36, 37]. The development of microhardness after HPT processing depends on the stacking fault energy of the alloy [10, 19]. The AZ91 alloy with a low stacking fault energy [38] shows a slow rate of dynamic recovery during processing at room temperature, thus strain hardening occurs at a fast rate during processing [20, 32]. The AZ91 alloy processed in HPT showed an earlier saturation in the microhardness distribution than for the AZ31 alloy [21] processed in HPT at room temperature. The stacking fault energy is lower, and the fraction of particles of $\beta$-phase is higher in the AZ91 alloy than for the AZ31 alloy [38, 39]. Therefore, the evolution of grain refinement and strain hardening occurred at faster rates in the AZ91 alloy than for the AZ31 alloy. The overall microhardness values for the alloy processed at $473 \mathrm{~K}$ were significantly lower than for their counterparts processed at 296 and $423 \mathrm{~K}$, due to the variation in dislocation density with processing temperature [14]. However, the level and homogeneity of strengthening are still higher when processing by HPT at elevated temperatures than observed in ECAP [26], and FSP [27], where strengthening has been lowered by dynamic recrystallization, over-ageing and precipitate coarsening [26, 27]. The microhardness distributions in the AZ91 alloy are heterogeneous along the through-thickness directions in the initial stage of deformation. This is supported by the differences in microstructural observations along this direction. A sufficient high number of turns may reduce heterogeneity, by filling the alloy in-between the anvils and achieving a significant sticking condition which then increases the deformation and microstructural homogeneity $[5,12,15$, $40,41]$. The distribution of microhardness along the vertical and horizontal cross-sections showed considerable consistency for the current alloy processed at each specific processing temperature. This indicates the development of microstructural homogeneity with increasing imposed strain at each condition [8]. This consistency in the AZ91 alloy has not been observed in the AZ31 alloy or AZ91 alloy processed by ECAP [26] and FSP [27]. This is attributed to the difference in the aluminium content and stacking fault energy in both alloys, which control the extent of grain refinement, dislocation density, achieved homogeneity and resultant mechanical properties [14, 21, 38]. The behaviour of strain hardening and homogeneity of microhardness in the AZ91 alloy follows a standard model of hardness evolution with increasing equivalent strain reported in earlier work [20].

\section{The effect of the equivalent strain on the Hall-Petch relation and dislocation density}

The increase in the equivalent strain resulted in an evolution in microstructure and a gradual development in the microhardness [10]. The strength of the alloy in terms of its microhardness improved significantly with grain refinement at room temperature. This proportionality has been expressed by the Hall-Petch relationship for hardness measurements: $H v=H_{0}+k_{H} d^{-1 / 2}$ [42]. The effect of grain refinement on the strength of the ultrafine-grained alloy AZ91 alloy showed a significant consistency with this Hall-Petch relationship. The material constants are $H_{0}=76 \mathrm{MPa}$ and $k_{H}=233 \mathrm{MPa} \mu \mathrm{m}^{1 / 2}$, which is relatively higher than those found for AZ31 and AZ61 alloys $\left(H_{0}=647-697 \mathrm{MPa}\right.$ and $\left.k_{H}=118-170 \mathrm{MPa} \mathrm{mm}^{1 / 2}\right)[7$, 22, 43]. Thus, the ultrafine-grained AZ91 alloy shows a relatively higher level of hardness than for AZ31 and AZ61 alloys processed by HPT and ECAP processing at room temperature and elevated temperatures [21, 22, 44]. The difference in $k_{H}$ can be attributed to the difference in alloying constituents in the mentioned alloys, where the high content of alloying element in the AZ91 alloy resulted in a lowering of its stacking fault and thus a finer microstructure and a higher dislocation density in the AZ91 alloy after processing than in the AZ61 and AZ31 alloy $[19,21,22]$. The evolution in dislocation density with increase of imposed strain in HPT has a major effect on the 
achieved strengthening in the AZ91 alloy. The evolution of dislocation density is affected by the fraction of nano-sized particles of $\beta$-phase, value of applied pressure in HPT, and value of stacking fault energy. The widely distributed $\beta$ phase fine particles are reported as acting as barriers for mobile dislocations during deformation [39]. The high value of applied pressure has also been reported to enhance the obstruction of defect migration in the processed material and then promotes the suppression of dislocation annihilation $[45,46]$. The low stacking fault energy in the AZ91 alloy leads to a significant inhibition of dislocation cross-slip, and formation of a high density of planar arrays of dislocations has also been reported [10, 38].

\section{Conclusions}

1. AZ91 magnesium alloy has been effectively processed in HPT processing at room temperature with an ultrafine-grained microstructure down to $35 \mathrm{~nm}$. The alloy processed at 423 and $473 \mathrm{~K}$ has been significantly refined by twinning segmentation of the original grains into fine grains with average apparent grain sizes of 180 and $250 \mathrm{~nm}$, respectively.

2. Fragmentation and alignment of the $\beta$-phase in the direction of torsional strain have been observed during processing. This phase has been refined down to nanometre sizes with a higher fraction as the number of turns increased, indicating the very high level of plastic deformation that is imparted to the alloy during HPT.

3. Existence of twins at all processing temperatures and their distribution was proportional to processing temperature and the number of turns. The occurrence of twinning has been induced by the need for re-orientation of the microstructure towards the slip direction and to accommodate severe plastic deformation.

4. Lower processing temperature has resulted in homogenous microstructure and significant development of strength. Higher processing temperatures have resulted in heterogeneous microstructures especially in the initial stages of HPT and this heterogeneity decreased gradually at higher numbers of turns.

5. A considerable dislocation density has developed with increasing the number of turns at lower processing temperature rather than at higher processing temperatures. The values of dislocation density after HPT were higher than earlier reported data for the same alloy.

6. The ultrafine-grained AZ91 alloy follows the HallPetch relationship, and this emphasizes the significant dependence of strength on grain size. The higher alloying content, fraction of nano-sized particles of $\beta$-phase and the dominance of basal slip and pyramidal modes after processing also have a significant effect on the strengthening of the alloy processed at $296 \mathrm{~K}$.

Acknowledgements One of the authors (Ahmed S. J. Al-Zubaydi) is grateful to The Higher Committee for Education Development (HCED) of the Government of Iraq for the provision of Ph.D. scholarship.

Funding This work was supported in part by the Russian Science Foundation under Grant No. 14-29-00199 (APZ).

\section{Compliance with ethical standards}

Conflict of Interest The authors declare that they have no conflict of interest.

Open Access This article is distributed under the terms of the Creative Commons Attribution 4.0 International License (http://creative commons.org/licenses/by/4.0/), which permits unrestricted use, distribution, and reproduction in any medium, provided you give appropriate credit to the original author(s) and the source, provide a link to the Creative Commons license, and indicate if changes were made.

\section{References}

1. Ravi Kumar NV, Blandin JJ, Desrayaud C, Montheillet F, Suéry M (2003) Grain refinement in AZ91 magnesium alloy during thermomechanical processing. Mater Sci Eng A 359:150-157

2. Yamashita A, Horita Z, Langdon TG (2001) Improving the mechanical properties of magnesium and a magnesium alloy through severe plastic deformation. Mater Sci Eng A 300:142-147

3. Kubota K, Mabuchi M, Higashi K (1999) Processing and mechanical properties of fine-grained magnesium alloys. J Mater Sci 34:2255-2262. doi:10.1023/A:1004561205627

4. Mabuchi M, Iwasaki H, Yanase K, Higashi K (1997) Low temperature superplasticity in an AZ91 magnesium alloy processed by ECAE. Scr Mater 36:681-686

5. Figueiredo RB, Langdon TG (2011) Development of structural heterogeneities in a magnesium alloy processed by high-pressure torsion. Mater Sci Eng A 528:4500-4506

6. Kai M, Horita Z, Langdon TG (2008) Developing grain refinement and superplasticity in a magnesium alloy processed by highpressure torsion. Mater Sci Eng A 488:117-124

7. Xia K, Wang JT, Wu X, Chen G, Gurvan M (2005) Equal channel angular pressing of magnesium alloy AZ31. Mater Sci Eng A 410-411:324-327

8. Valiev RZ, Zhilyaev AP, Langdon TG (2013) Bulk nanostructured materials: fundamentals and applications. Wiley, New Jersey

9. Gubicza J, Máthis K, Hegedűs Z, Ribárik G, Tóth AL (2010) Inhomogeneous evolution of microstructure in AZ91 Mg-alloy during high temperature equal-channel angular pressing. J Alloy Compd 492:166-172

10. Zhilyaev AP, Langdon TG (2008) Using high-pressure torsion for metal processing: fundamentals and applications. Prog Mater Sci 53:893-979

11. Vander Voort GF (2004) Metals handbook: metallography and microstructures, vol 9. ASM International, Cleveland

12. Kawasaki M, Figueiredo RB, Langdon TG (2011) An investigation of hardness homogeneity throughout disks processed by high-pressure torsion. Acta Mater 59:308-316 
13. Al-Zubaydi ASJ, Zhilyaev AP, Wang SC, Reed PAS (2015) Superplastic behaviour of AZ91 magnesium alloy processed by high-pressure torsion. Mater Sci Eng A 637:1-11

14. Máthis K, Gubicza J, Nam NH (2005) Microstructure and mechanical behavior of AZ91 Mg alloy processed by equal channel angular pressing. J Alloy Compd 394:194-199

15. Hohenwarter A, Bachmaier A, Gludovatz B, Scheriau S, Pippan $\mathrm{R}$ (2009) Technical parameters affecting grain refinement by high pressure torsion. Int J Mater Res 100:1653-1661

16. Myshlyaev MM, McQueen HJ, Mwembela A, Konopleva E (2002) Twinning, dynamic recovery and recrystallization in hot worked Mg-Al-Zn alloy. Mater Sci Eng A 337:121-133

17. del Valle JA, Pérez-Prado MT, Ruano OA (2003) Texture evolution during large-strain hot rolling of the Mg AZ61 alloy. Mater Sci Eng A 355:68-78

18. Al-Samman T, Gottstein G (2008) Room temperature formability of a magnesium AZ31 alloy: examining the role of texture on the deformation mechanisms. Mater Sci Eng A 488:406-414

19. Zhao YH, Liao XZ, Zhu YT, Horita Z, Langdon TG (2005) Influence of stacking fault energy on nanostructure formation under high pressure torsion. Mater Sci Eng A 410-411:188-193

20. Kawasaki M, Figueiredo RB, Huang Y, Langdon TG (2014) Interpretation of hardness evolution in metals processed by highpressure torsion. J Mater Sci 49:6586-6596. doi:10.1007/s10853014-8262-8

21. Stráská J, Janeček M, Gubicza J, Krajňák T, Yoon EY, Kim HS (2015) Evolution of microstructure and hardness in AZ31 alloy processed by high pressure torsion. Mater Sci Eng A 625:98-106

22. Harai Y, Kai M, Kaneko K, Horita Z, Langdon TG (2008) Microstructural and mechanical characteristics of AZ61 magnesium alloy processed by high-pressure torsion. Mater Trans 49:76-83

23. Matsubara K, Miyahara Y, Horita Z, Langdon TG (2003) Developing superplasticity in a magnesium alloy through a combination of extrusion and ECAP. Acta Mater 51:3073-3084

24. Braszczyńska-Malik KN, Froyen L (2005) Microstructure of AZ91 alloy deformed by equal channel angular pressing. Int $\mathbf{J}$ Mater Res (former: Zeitschrift für Metallkunde) 96:913-917

25. Braszczyńska-Malik KN (2009) Spherical shape of $\gamma$-Mg17Al12 precipitates in AZ91 magnesium alloy processed by equalchannel angular pressing. J Alloy Compd 487:263-268

26. Zhao Z, Chen Q, Hu C, Shu D (2009) Microstructure and mechanical properties of SPD-processed an as-cast AZ91D + Y magnesium alloy by equal channel angular extrusion and multiaxial forging. Mater Des 30:4557-4561

27. Cavaliere P, De Marco PP (2007) Superplastic behaviour of friction stir processed AZ91 magnesium alloy produced by high pressure die cast. J Mater Process Technol 184:77-83

28. Pérez-Prado MT, Valle D, Ruano OA (2004) Grain refinement of $\mathrm{Mg}-\mathrm{Al}-\mathrm{Zn}$ alloys via accumulative roll bonding. Scr Mater 51:1093-1097

29. Kim WJ, Hong SI, Kim YH (2012) Enhancement of the strain hardening ability in ultrafine grained $\mathrm{Mg}$ alloys with high strength. Scr Mater 67:689-692

30. Figueiredo RB, Pereira PHR, Aguilar MTP, Cetlin PR, Langdon TG (2012) Using finite element modeling to examine the temperature distribution in quasi-constrained high-pressure torsion. Acta Mater 60:3190-3198
31. Edalati K, Miresmaeili R, Horita Z, Kanayama H, Pippan R (2011) Significance of temperature increase in processing by high-pressure torsion. Mater Sci Eng A 528:7301-7305

32. Al-Zubaydi A, Figueiredo RB, Huang Y, Langdon TG (2013) Structural and hardness inhomogeneities in $\mathrm{Mg}$-Al-Zn alloys processed by high-pressure torsion. J Mater Sci 48:4661-4670. doi:10.1007/s10853-013-7176-1

33. Zhilyaev AP, Nurislamova GV, Kim B-K, Baró MD, Szpunar JA, Langdon TG (2003) Experimental parameters influencing grain refinement and microstructural evolution during high-pressure torsion. Acta Mater 51:753-765

34. Zhilyaev AP, Oh-ishi K, Langdon TG, McNelley TR (2005) Microstructural evolution in commercial purity aluminum during high-pressure torsion. Mater Sci Eng A 410-411:277-280

35. Zhilyaev AP, Lee S, Nurislamova GV, Valiev RZ, Langdon TG (2001) Microhardness and microstructural evolution in pure nickel during high-pressure torsion. Scr Mater 44:2753-2758

36. Vorhauer A, Pippan R (2004) On the homogeneity of deformation by high pressure torsion. Scr Mater 51:921-925

37. Huang Y, Kawasaki M, Langdon TG (2013) Influence of anvil alignment on shearing patterns in high-pressure torsion. Adv Eng Mater 15:1-755

38. Somekawa H, Hirai K, Watanabe $\mathrm{H}$, Takigawa $\mathrm{Y}$, Higashi $\mathrm{K}$ (2005) Dislocation creep behavior in $\mathrm{Mg}-\mathrm{Al}-\mathrm{Zn}$ alloys. Mater Sci Eng A 407:53-61

39. Tahreen N, Chen DL, Nouri M, Li DY (2014) Effects of aluminum content and strain rate on strain hardening behavior of cast magnesium alloys during compression. Mater Sci Eng A 594:235-245

40. Figueiredo RB, Aguilar MTP, Cetlin PR, Langdon TG (2012) Analysis of plastic flow during high-pressure torsion. J Mater Sci 47:7807-7814. doi:10.1007/s10853-012-6506-Z

41. Kawasaki M, Figueiredo RB, Langdon TG (2012) Twenty-five years of severe plastic deformation: recent developments in evaluating the degree of homogeneity through the thickness of disks processed by high-pressure torsion. J Mater Sci 47: 7719-7725. doi:10.1007/s10853-012-6507-y

42. Furukawa M, Horita Z, Nemoto M, Valiev RZ, Langdon TG (1996) Microhardness measurements and the Hall-Petch relationship in an Al-Mg alloy with submicrometer grain size. Acta Mater 44:4619-4629

43. Xu J, Shirooyeh M, Wongsa-Ngam J, Shan D, Guo B, Langdon TG (2013) Hardness homogeneity and micro-tensile behavior in a magnesium AZ31 alloy processed by equal-channel angular pressing. Mater Sci Eng A 586:108-114

44. Chang S-Y, Lee S-W, Kang KM, Kamado S, Kojima Y (2004) Improvement of mechanical characteristics in severely plasticdeformed Mg alloys. Mater Trans 45:488-492

45. Setman D, Schafler E, Korznikova E, Zehetbauer MJ (2008) The presence and nature of vacancy type defects in nanometals detained by severe plastic deformation. Mater Sci Eng A 493:116-122

46. Gubicza J, Dobatkin SV, Khosravi E, Kuznetsov AA, Lábár JL (2011) Microstructural stability of $\mathrm{Cu}$ processed by different routes of severe plastic deformation. Mater Sci Eng A 528:1828-1832 